\title{
“VOCÊ APRENDE INGLÊS NA ESCOLA?” “DAQUELE JEITO, NÉ?”: PERCEPÇÕES SOBRE $O$ ENSINO-APRENDIZAGEM DE LÍNGUA ESTRANGEIRA NA ESCOLA PÚBLICA*
}

\author{
"SE APRENDE INGLÉS EN LA ESCUELA?" "DE AQUELLA MANERA, NO?": PERCEPCIONES DE LA \\ ENSEÑANZA Y EL APRENDIZAJE DE LENGUA EXTRANJERA EN LA ESCUELA PÚBLICA
"DO YOU LEARN ENGLISH AT SCHOOL?" “SORT OF”: PERCEPTIONS ON FOREIGN LANGUAGE TEACHING-LEARNING IN PUBLIC SCHOOLS

\author{
Cristina Helena Miranda** \\ Patrícia Silva Cardoso*** \\ Marimar da Silva****
}

Universidade Federal de Santa Catarina - UFSC, Florianópolis, BR

\begin{abstract}
RESUMO: Inserido na linha de formação profissional reflexiva crítica, este estudo apresenta o resultado de uma investigação conduzida por professores em formação inicial em seu futuro contexto de estágio de docência, a escola pública. A investigação, de base qualitativa interpretativa, proposta pela disciplina de Estágio Supervisionado do Curso de Licenciatura em Letras/Inglês da Universidade Federal de Santa Catarina, na modalidade a distância, busca uma compreensão da escola campo de estágio por meio da percepção de seus atores sobre as práticas de ensino-aprendizagem de língua estrangeira/inglês, visando simultaneamente à elaboração de aulas socialmente situadas para o contexto investigado e à formação do profissional reflexivo e crítico. O corpus, coletado durante o primeiro semestre de 2012, constituiu-se de entrevistas semiestruturadas e conversas informais com os participantes, de notas de campo e do estudo do Projeto Político Pedagógico da escola. O estudo identificou inconsistências entre a proposta teórica do Projeto Político Pedagógico da escola para o ensino-aprendizagem de língua estrangeira/inglês e as percepções que os participantes têm desse processo na prática, e sinalizou um viés para as intervenções pedagógicas. Com base nos resultados, o estudo sugere uma abordagem holística para o ensino-aprendizagem de língua estrangeira/inglês, partindo de temas socialmente relevantes para o estágio de docência no contexto investigado, e valida o modelo de formação reflexivo crítico proposto pela disciplina de Estágio Supervisionado.
\end{abstract}

PALAVRAS-CHAVE: formação inicial de professores; ensino-aprendizagem de inglês na escola pública; ensino reflexivo crítico.

RESUMEN: Insertado en la línea de formación reflexiva crítica, este estudio presenta los resultados de una investigación llevada a cabo por profesores en formación inicial en su futuro contexto de fase de docencia, la escuela pública. La investigación, de base cualitativa interpretativa, propuesta por la disciplina de Etapa supervisada del curso de Licenciatura en Letras/Inglés de la Universidad Federal de Santa Catarina, en la modalidad a distancia, busca una comprensión de la escuela como campo de prácticas a través de la percepción de los actores sobre las prácticas de enseñanza y aprendizaje de la lengua extranjera/Inglés, simultáneamente con el objetivo a la elaboración de aulas socialmente situadas para el contexto investigado y a la formación del profesional reflexivo y crítico. El corpus recogido durante el primer semestre de 2012, consistió en entrevistas semiestructuradas y conversaciones informales con los participantes, de notas de campo y del estudio del Proyecto Político Pedagógico de la escuela. El estudio identificó inconsistencias entre la propuesta teórica del Proyecto Político Pedagógico de la escuela para la enseñanza y el aprendizaje de la lengua extranjera/Inglés y las percepciones que tienen los participantes de este proceso en la práctica, y se señaló una inclinación para las intervenciones pedagógicas. Basándose en los resultados, el estudio sugiere un enfoque holístico para la enseñanza y el aprendizaje de la lengua extranjera/Inglés, a partir de temas de relevancia social para las prácticas docente en el contexto investigado, y validar el modelo de formación reflexivo crítico propuesto por la disciplina de prácticas supervisadas.

PALABRAS-CLAVE: formación inicial de profesores; enseñanza y aprendizaje de inglés en la escuela pública; enseñanza reflexiva crítica.

ABSTRACT: Inserted in the area of critical reflective professional education, this study presents the results of an investigation conducted by pre-service teachers in the context of their future teaching practicum, the public school. The research, qualitative interpretative in nature, proposed by the Teaching Practicum discipline of the Language Arts Course, in the distance mode, of the Federal University of Santa Catarina, seeks for a further understanding of the school context through the perception of their actors on the teaching-learning of English as a foreign language, with a view to elaborating socially situated lessons and educating the critical reflective practitioner as well. The corpus, collected during the first semester of 2012, consisted of semi-structured interviews and informal conversations with the participants, field notes and the study of the Educational Policy Project of the

\footnotetext{
* Os trechos entre aspas correspondem a um comentário de uma aluna participante da pesquisa sobre o ensino-aprendizagem de inglês na escola pública.

** Graduanda do Curso de Licenciatura em Letras/Inglês, na modalidade a distância, da UFSC. Email: cristinapolouabsj@gmail.com.

*** Graduanda do Curso de Licenciatura em Letras/Inglês, na modalidade a distância, da UFSC. Email: patriciamessinauab@gmail.com.

**** Professora Doutora Convidada do Centro de Comunicação e Expressão, da UFSC, com atuação no Grupo de pesquisa TEMA DIDÁTICO Tecnologia, Educação e Materiais Didáticos. Email: marimardasilva@gmail.com.
} 
investigated context. The study identified inconsistencies between the theoretical proposal of the school Educational Policy Project, regarding the teaching-learning of English as a foreign language, and the participants' perceptions of this process in practice, and pointed out a fertile terrain for pedagogical interventions. Based on the results, the study suggests a holistic approach to the teaching-learning of English as a foreign language, departing from socially relevant themes for the teaching practicum in the investigated context, and validates the critical reflexive model of education proposed by the Teaching Practicum discipline.

KEYWORDS: pre-service teachers' perceptions; english teaching-learning in public school; critical reflective teaching.

\section{INTRODUÇÃO}

Desde o fim da década de 1980, estudos na área de formação de professores (como por exemplo, ALMEIDA FILHO, 1999; BARTLETT, 1990; GIMENEZ, 2002; JOHNSON; FREEMAN, 2001; MOITA LOPES, 1996; NÓVOA, 2009; LIBERALI, 2008; RICHARDS, 1998; SCHÖN, 1983; SMYTH, 1992; WALLACE, 1991; ZEICHNER; LISTON, 1987 entre outros), vêm propondo a formação de profissionais reflexivos, visando a atender com mais propriedade as demandas da sociedade pós-moderna. Para tanto, práticas como ações reflexivas sobre o fazer pedagógico (BARTLETT, 1990; LIBERALI, 2008; SMYTH, 1992), instrumentos de reflexão sobre a prática do professor (ABRAHÃO 2002; CRUZ; REIS, 2002; LIBERALI, 2002; RICHARDS, 1990; ORTENZI, MATEUS; REIS, 2002), procedimentos investigativos sobre a abordagem de ensino (ALMEIDA FILHO, 1999) e de crenças do professor (Barcelos, 1999; Gimenez, 1999), além de pesquisas qualitativas de base etnográfica (MOITA LOPES, 1996; SILVA, 2009; TELLES, 2002) vêm sendo usadas em cursos de formação, instigando, simultaneamente, o desenvolvimento pessoal e profissional contínuo do professor.

Inserido nessa linha de formação profissional reflexiva, este estudo apresenta o resultado de uma investigação conduzida por professores em formação inicial em seu futuro contexto de estágio de docência. A investigação, de base etnográfica, foi proposta pela disciplina de Estágio Supervisionado do Curso de Licenciatura em Letras/Inglês da Universidade Federal de Santa Catarina, na modalidade a distância, como forma de levar os futuros professores a refletir de forma sistematizada e crítica sobre práticas de ensinoaprendizagem de língua estrangeira/inglês no contexto da escola pública. Acreditamos que a partir da compreensão advinda da investigação do contexto de estágio, os futuros professores têm mais e melhores condições de planejar e implementar aulas voltadas às necessidades e potencialidades dos alunos e às vocações do contexto, assim como de avaliar com mais precisão os resultados obtidos e de dar continuidade ao seu desenvolvimento pessoal e profissional com mais autonomia.

Este artigo está organizado em cinco seções. Na primeira, apresentamos brevemente a área na qual este estudo está inserido; na segunda, mostramos o cenário atual da área de formação de professores ao mesmo tempo que justificamos a investigação proposta pela disciplina de Estágio Supervisionado; na terceira, descrevemos o contexto do estudo, que inclui a disciplina de Estágio Supervisionado, a escola campo de estágio, os participantes do estudo e os instrumentos de coleta de dados; na quarta, apresentamos e discutimos os resultados da investigação feita; e, na quinta, com base nos resultados, fazemos algumas considerações finais.

\section{A FORMAÇÃO DO PROFESSOR: DESENHANDO O CENÁRIO}

Impulsionada pelas demandas sociais e resultados de pesquisas sobre ensino-aprendizagem, a forma como os professores vêm sendo preparados para ensinar vem mudando ao longo dos anos. Na sociedade pósmoderna, a proposta é o modelo reflexivo.

O modelo reflexivo idealizado por Wallace (1991) propõe que os cursos de formação articulem conhecimento teórico e saberes práticos por meio de um ciclo reflexivo composto de dois elementos: a reflexão e a prática, no qual um elemento dialoga com o outro em busca de uma competência profissional de natureza dinâmica, um projeto a ser desenvolvido ao longo da vida do professor. O modelo está fundamentado em uma visão de aprendizagem como construção de conhecimentos (FREEMAN, 2001) e de conhecimento docente como teorias advindas da pesquisa científica e dos saberes que emergem da prática e na prática (ALMEIDA FILHO, 1999; ELBAZ, 1981; RICHARDS, 1998). Além disso, o modelo concebe o aprendiz como um indivíduo repleto de saberes que filtram e impactam a forma como ele aprende (BARCELOS, 1999; GIMENEZ, 1999; SILVA 2005) e o professor como mediador desse processo. 
Assim, em um modelo que concebe a aprendizagem como construção de conhecimento e o aprendiz como agente desse processo, formar o professor é criar condições para que ele aprenda a ensinar ensinando, praticando as atividades de ensino e de aprendizagem dentro do contexto onde elas ocorrem e refletindo sobre elas da perspectiva de quem ensina e aprende (JOHNSON; FREEMAN, 2001). Dessa forma, o ensino (e também a formação profissional) se amalgama àquele que aprende, à sua vida, à forma como aprende e ao contexto social no qual está inserido (SILVA, 2011); uma mudança radical de conceitos e de forma de ensinar, se comparada aos pacotes fechados de técnicas de ensino usados no modelo de ciência aplicada, no qual concepções de ensino como transmissão de conhecimento e de aluno como ser passivo diante da aprendizagem, orientaram fortemente a formação de professores no século passado.

No cenário atual, então, não existem fórmulas prontas para aprender a ensinar, a mediar o processo de aprendizagem ou a refletir para aprender continuamente, existem orientações que emergem de teorias e pesquisas sobre ensino e aprendizagem (SILVA, 2011). Estudiosos da área de formação de professores (como FREIRE, 2005; NÓVOA, 2009, por exemplo) vêm propondo diferentes maneiras para ensinar o futuro professor a ser um profissional não apenas reflexivo mas também crítico e, dessa forma, aprender continuamente.

Segundo Silva (2009; 2011), as propostas na linha de formação reflexiva crítica podem ser agrupadas em três categorias: a formação com foco na articulação de diferentes domínios de conhecimentos, a formação com foco no professor pesquisador da prática e a formação com foco em ações e instrumentos reflexivos. A primeira categoria de formação propõe uma articulação de diferentes domínios de conhecimento durante o processo de formação inicial. Nessa categoria, destacam-se os estudos de Richards (1998) e Johnson e Freeman (2001). O primeiro sugere um modelo de formação articulado a seis domínios de conhecimentos básicos que se sobrepõem, a saber, o conhecimento de teorias de ensino, habilidades de ensino, habilidades comunicativas, de linguagem, de pedagogia e do contexto social. O segundo, por sua vez, propõe um modelo de formação socialmente situada articulado a três grandes domínios de conhecimento, a citar, o conhecimento do aprendiz, do contexto da escola e do contexto educacional onde a escola está inserida, e as atividades de ensino e de aprendizagem no local onde elas realmente ocorrem.

A segunda categoria de formação propõe a integração de pesquisa qualitativa nos cursos de formação de professores. Nessa categoria, estão os estudos de Almeida Filho (1999), Moita Lopes (1996), Silva (2009; 2011) e Telles (2002; 2004). Almeida Filho propõe um modelo de procedimentos de análise de abordagem de ensino, visando a revelar as concepções que subjazem a abordagem de ensino do professor. Argumenta o autor que, se o professor conseguir descrever, analisar e explicar sua abordagem de ensino e desvelar a configuração das competências que impulsiona o seu fazer pedagógico, ele poderá iniciar uma trajetória de iluminações, ou seja, uma prática com inovações e reflexões que podem levá-lo a um novo fazer na sala de aula. Moita Lopes, por sua vez, sugere integrar a pesquisa-ação no processo de aprender a ensinar, argumentando que a formação teórico e crítica do professor de línguas deve envolver dois tipos de conhecimento, a saber, o conhecimento sobre a natureza da linguagem na sala de aula e fora dela, e o de como atuar na produção de conhecimento sobre o uso da linguagem na sala de aula, além de conhecimentos advindos da Sociologia e da Psicologia. Já Silva propõe integrar a pesquisa qualitativa interpretativa de base etnográfica simultaneamente à disciplina de Estágio Supervisionado nos cursos de Licenciatura em Letras, no sentido de formar o professor pesquisador na/da prática. A pesquisadora argumenta que formar professores pesquisadores favorece a aprendizagem da reflexão sistemática sobre a prática, o desenvolvimento pessoal e profissional do futuro professor de forma contínua, além de criar condições para o planejamento, implementação e avaliação de aulas socialmente situadas durante o estágio de docência. E Telles enfatiza que durante a formação inicial é fundamental que os professores tragam à tona suas concepções, conhecimentos e crenças sobre ensino e aprendizagem. Para isso, propõe dois tipos de pesquisa qualitativa, a pesquisa narrativa e a pesquisa educacional com base nas artes. No primeiro tipo de pesquisa, as histórias que os professores contam sobre suas experiências de ensino e aprendizagem ao longo da vida fazem emergir suas identidades e, no segundo tipo, a arte como o drama e a fotografia, por exemplo, desempenham a mesma função, abrindo espaço para intervenções, visando à mudança de concepções.

A terceira categoria de formação, a que foca em ações reflexivas, acredita que tais ações desenvolvem o pensamento crítico do professor. Nessa categoria, estão os estudos de Bartlett (1990), Smyth (1992) e Liberali (2008). Com base na pedagogia crítica de Paulo Freire (2005), esses pesquisadores sugerem um ciclo de ações, a citar, descrever, informar, confrontar e reconstruir, para serem usadas em diferentes momentos de reflexão sobre a prática pedagógica do professor. No primeiro momento, o professor descreve sua prática, tendo como guia a pergunta: o que eu faço nessa aula? No segundo momento, o professor 
informa o que faz na prática, guiado pela pergunta: o que o meu fazer pedagógico significa? No terceiro momento, o professor confronta o que faz na prática, respondendo à pergunta: como vim a ser o que sou como professor? E no quarto momento, o professor reconstrói o que faz na prática, tendo como orientação da reflexão a pergunta: como eu posso tornar a minha prática diferente?

Outros estudiosos (por exemplo, ABRAHÃO, 2002; CRUZ; REIS, 2002; LIBERALI, 2002; MAGALHÃES, 2002; RICHARDS, 1990; ORTENZI, MATEUS; REIS, 2002) ainda propõem a inserção de instrumentos reflexivos para guiar a formação inicial de professores. Entre esses instrumentos, podemos citar os diários, portfólios, sessões de visionamento, leitura de textos seguida de discussão, automonitoramento, narrativas e biografias. Os pesquisadores argumentam que se os professores aprenderem a fazer anotações sobre a prática em diários, a organizar portfólios com os registros e atividades de ensino-aprendizagem, a gravar suas aulas para analisá-las posteriormente, a narrar suas histórias de vida, a escrever sua biografia e a refletir sobre esses dados, eles poderão aprender a refletir com sistematicidade sobre o seu ensino e a aprendizagem de seus alunos, a identificar problemas na prática, a articular teoria e prática, na medida em que tentam entender e explicar seus registros e fazeres na prática, e a provocar mudanças em seu contexto de ensino. Ademais, argumentam que, na ausência de parceiros no processo de reflexão, os instrumentos reflexivos podem servir como uma espécie de interlocutor, alguém com quem o professor pode dividir suas dúvidas e questionamentos sobre a prática.

Então, visando à formação do professor reflexivo e crítico, a disciplina de Estágio Supervisionado, do Curso de Licenciatura em Letras/Inglês, da Universidade Federal de Santa Catarina, na modalidade a distância, propõe a formação do professor pesquisador da prática. Assim, este artigo tem por objetivo trazer os resultados de parte desse processo de formação. Mais precisamente, o artigo traz os resultados do estudo que teve como objetivo principal levar os futuros professores a compreender o contexto da escola pública, visando à construção de aulas socialmente situadas para o estágio de docência de língua estrangeira/inglês. A busca da compreensão desse contexto inicia com a descrição do método usado para o estudo, que ora apresentamos.

\section{PERCEPÇÕES: EM BUSCA DA COMPREENSÃO DO CONTEXTO}

Este estudo, de base qualitativa interpretativa, busca uma compreensão do contexto da escola campo de estágio por meio da percepção dos atores desse contexto, as professoras de inglês, Maria e Mariana, e os alunos do Ensino Médio noturno, sobre suas experiências de ensino-aprendizagem de inglês naquele contexto.

Como o estudo se apoia no conceito de percepção, é de fundamental importância defini-lo. Para isso, trazemos o conceito de percepção de Silva (2003, p.9). ${ }^{1}$ Para a autora,

(...) percepção é um processo altamente subjetivo relacionado a experiências pessoais, crenças e interpretações, uma forma particular de sabermos o que acontece ao nosso redor. Percepção refere-se a um processo que se inicia com sensações, que envolvem o registro e a decodificação de vários estímulos percebidos pelos órgãos sensoriais, até a experiência completa da compreensão. Percepção, dessa forma, envolve a habilidade de elaborar, interpretar e atribuir significado ao insumo recebido.

Em outras palavras, este estudo visa a estudar as percepções dos participantes em seu ambiente natural, tentando fazer sentido ou interpretando o fenômeno sob investigação, com base nos significados que trazem.

Sabemos que os indivíduos raramente conseguem explicar totalmente suas ações ou intenções; o que eles podem oferecer são histórias sobre o que fizeram e porquê fizeram o que fizeram (DENZIN; LINCOLN, 1998). Sabemos também que nenhum método pode contemplar todas as variações sutis que ocorrem durante as experiências humanas. Por isso, cruzando dados de diferentes fontes, como entrevistas semiestruturadas, conversas informais, notas de campo, estudo do Projeto Político Pedagógico (doravante

\footnotetext{
1 (...) perception - that is, what is perceived - is highly subjective because it is related to personal experiences, beliefs, and interpretations, a unique way in which we come to know what is going on around us. Perception refers to the entire sequence from initial sensations, which involve registering and coding of various stimuli perceived by the sensory organs, to the full experience of understanding. Perception, then, involves our ability to elaborate, interpret, and assign meaning to the input we receive. (SILVA, 2003, p.9).
} 
PPP) da escola, tentaremos atribuir significado às percepções dos participantes sobre o ensino e a aprendizagem da língua estrangeira/inglês na escola campo de estágio, no sentido de compreender o contexto para a preparação de aulas voltadas às necessidades e potencialidades dos alunos e às vocações desse contexto.

Guiam este estudo as seguintes perguntas: Quais são as orientações do Projeto Político Pedagógico da escola campo de estágio em relação ao ensino-aprendizagem de língua estrangeira/inglês? Quais são as percepções dos participantes em relação ao ensino e à aprendizagem da língua estrangeira/inglês na escola campo de estágio? As respostas a essas perguntas visam a iluminar o estágio de docência dos professores de inglês em formação inicial, na modalidade a distância.

\subsection{A disciplina de Estágio Supervisionado: uma proposta de formação profissional reflexiva crítica}

A disciplina de Estágio Supervisionado, do Curso de Licenciatura em Letras/Inglês, da Universidade Federal de Santa Catarina, na modalidade a distância, uma disciplina com carga horária de quatrocentos e oitenta e seis horas (486h), propõe que o professor em formação inicial aprenda a ser ambos: o professor de inglês e o pesquisador de sua prática. Nesse sentido, a disciplina foi organizada em três módulos e ministrada durante um ano e meio, do primeiro semestre de 2012 ao primeiro semestre de 2013.

No primeiro módulo, o foco maior da disciplina foi na formação do professor pesquisador da prática. Para isso, os futuros professores pesquisadores estudaram abordagens de pesquisa na sala de aula e conduziram um estudo investigativo sobre processo de ensino-aprendizagem de língua estrangeira/inglês na escola campo de estágio, para desenvolver posteriormente seu estágio de docência de forma socialmente situada. O estudo investigativo no primeiro módulo da disciplina também teve como objetivo revelar ao professor orientador de estágio o contexto no qual os futuros professores iriam fazer suas intervenções pedagógicas, para que a orientação de estágio também pudesse estar voltada para as necessidades daquele contexto.

No segundo módulo, o foco foi na compreensão da sala de aula de língua estrangeira/inglês por meio da observação da prática de um professor mais experiente e seus alunos. Para esse momento, os futuros professores pesquisadores desenvolveram tarefas de observação focada na sala de aula e elaboraram relatos reflexivos do que lá ocorria. Com base nos dados obtidos no primeiro e no segundo módulo, os futuros professores elaboraram um projeto de ensino de língua estrangeira a ser implementado no módulo subsequente. Igualmente, as tarefas de observação focadas tiveram como objetivo revelar ao professor orientador de estágio quem eram os agentes do contexto, como aprendiam e ensinavam a língua estrangeira/inglês, para que as futuras intervenções pudessem atender as necessidades e/ou desenvolver as potencialidades daqueles agentes naquele contexto.

No terceiro módulo, o foco foi no estágio de docência. Nesse momento, os professores estagiários desenvolveram o plano de ensino, elaborando e implementando aulas e posteriormente avaliando as aula e as tarefas de ensino-aprendizagem para a turma de alunos que observaram no módulo anterior da disciplina.

Por fim, por considerar basilar do ensino formal o desenvolvimento da consciência sobre como a linguagem se articula em ação humana sobre o mundo por meio do discurso (a exemplo de MOITA LOPES, 1996; MEURER, 2002), a disciplina de Estágio Supervisionado propôs a abordagem comunicativa por meio de temas socialmente relevantes para o ensino-aprendizagem de inglês na escola campo de estágio. Guiaram essa abordagem, a concepção de língua como discurso, ou seja, língua em uso em diferentes práticas sociais, e a concepção de aprendizagem como construção e conhecimento, tendo como agente o próprio aluno e como mediador intelectual do processo o professor (GIROUX, 1987).

Cabe ainda ressaltar que o estudo que ora apresentamos está focado apenas no primeiro módulo da disciplina de Estágio Supervisionado, já que quando da sua elaboração o segundo módulo ainda não havia iniciado. Isso significa dizer que os dados aqui apresentados resultam do estudo PPP da escola e das percepções dos alunos e das professoras de inglês sobre o ensino-aprendizagem no contexto investigado, não da observação do processo de ensinar e aprender dentro da sala de aula pelas pesquisadoras. 


\subsection{A escola campo de estágio: o contexto e seus atores}

A escola de Educação Básica contexto deste estudo está localizada na região metropolitana de Florianópolis. O bairro no qual está inserida, embora em crescente desenvolvimento no ramo imobiliário, é formado por famílias de classe média-baixa e baixa. A escola, localizada próxima a um lixão, atende a 800 alunos e vem investindo em infraestrutura e recursos humanos, visando a melhorar as condições não só do ensino, com a implantação, em 2012, do Ensino Médio Inovador (EMI), como também do entorno, com projetos de reciclagem, empreendedorismo e o programa Escola Aberta. Os reflexos desse investimento já começaram a aparecer, conforme mostra o excerto da entrevista com a gestora escolar, no primeiro semestre de 2012: “A escola ficou em $3^{\circ}$ lugar no ranking do Exame Nacional do Ensino Médio (ENEM), em 2010, o $4^{\circ}$ lugar na grande Florianópolis, e $25 \%$ dos alunos foram aprovados em vestibulares de duas importantes universidades da região: a Universidade do Estado de Santa Catarina (UDESC) e a Universidade Federal de Santa Catarina (UFSC)”.

Participaram do estudo duas professoras de inglês e oito alunos do Ensino Médio noturno do contexto investigado. Os dados foram coletados por meio de entrevistas semiestruturadas e conversas informais com os participantes, que receberam nomes fictícios para preservar suas identidades As entrevistas com as professoras foram feitas na sala dos professores da escola e as conversas informais com os alunos foram feitas durante a pausa para o recreio escolar.

A professora Maria, uma das participantes da pesquisa, tem licenciatura dupla em Letras (Português e Inglês), graduação concluída há trinta anos, e é efetiva da rede pública de ensino do Estado de Santa Catarina. No entanto, trabalha como professora de inglês há sete anos apenas. Já a professora Mariana, a outra participante da pesquisa, com formação recente em Pedagogia, foi contratada para dar aulas de empreendedorismo para as turmas do EMI, e posteriormente convidada a dar aula de inglês, devido à falta de professor de inglês disponível na escola.

Em relação aos alunos participantes, dado o caráter exploratório do estudo, estes não foram selecionados previamente, mas abordados aleatoriamente para conversas informais. O estudo do perfil dos alunos do Ensino Médio do período noturno mostra que a maioria dos matriculados já trabalha e tem idade máxima de 20 anos, portanto os oito participantes de séries diversas, embora poucos, representam bem o grupo. A princípio distantes, depois curiosos com as fotos que as pesquisadoras tiravam, os diversos alunos que se aproximaram tornaram-se mais falantes após se acostumarem com sua presença na hora do recreio escolar, em especial aqueles cujas falas foram reproduzidas, pois sentiram que podiam dar voz aos seus sentimentos e expor suas opiniões.

\subsection{O corpus}

O corpus, coletado durante o primeiro semestre de 2012, constituiu-se de entrevistas com as professoras participantes, que receberam pseudônimos para preservar sua identidade, e com outros agentes desse contexto, como a gestora e a orientadora pedagógica da escola. Também fizeram parte do corpus as conversas informais com os alunos, que igualmente receberam nomes fictícios, e as notas de campo feitas pelas pesquisadoras, além do estudo do Projeto Político Pedagógico da escola investigada. A escolha de diferentes fontes de informação visaram à triangulação dos dados, oferecendo assim validação dos resultados obtidos.

Devido à natureza do estudo, os dados coletados foram lidos e categorizados. Dessa categorização, dois temas inter-relacionados emergiram: i) o contexto, os documentos e as práticas: (in)consistências entre o ideal e o real; ii) o contexto, a língua inglesa e as práticas: relações (des)conexas.

Ainda, devido à modalidade do Curso de Licenciatura ser a distância, a análise dos dados foi realizada principalmente via web. Para isso, buscamos estratégias de discussão e trocas de informações por meio de ferramentas que nos possibilitassem a escritura do texto de forma colaborativa e a interatividade síncrona e assíncrona. Das ferramentas colocadas à nossa disposição, usamos as de comunicação da Webtools, como Google Docs, Gtalk e o recurso de mensagens pelo Moodle, plataforma de e-learning na qual são desenvolvidos ambientes de aprendizagem virtuais. Além dos diálogos online, participamos dos fóruns de discussão abertos na plataforma, que funcionaram como canais de comunicação com os tutores e a professora orientadora de estágio supervisionado. As mensagens enviadas através do Moodle otimizaram o tempo da resposta das 
dúvidas mais urgentes, provando ser uma ferramenta eficiente para esse fim. Por outro lado, as discussões nos fóruns provaram ser mais ricas, já que abriram espaço para a interação com licenciandos do mesmo curso, porém de outras regiões do Estado de Santa Catarina, já que a UFSC ofereceu o curso simultaneamente para Chapecó, Concórdia, Araranguá, Itajaí e São José. Na sequência, apresentamos a análise e a discussão dos dados.

\section{ENTRE O IDEAL E O REAL: ANÁLISE E DISCUSSÃO DOS DADOS}

A partir do processo de categorização, emergiram dois temas inter-relacionados: i) o contexto, os documentos e as práticas: (in)consistências entre o ideal e o real; ii) o contexto, a língua inglesa e as práticas: relações (des)conexas, que passamos a comentar.

\subsection{O contexto, os documentos e as práticas: (in)consistências entre o ideal e o real}

Como mencionado anteriormente, a escola de Educação Básica contexto deste estudo vem investindo em infraestrutura e em recursos humanos, visando a melhorar as condições do ensino dentro da escola e no seu entorno com projetos voltados para problemas socialmente relevantes. No entanto, especificamente em relação à língua inglesa, o estudo do PPP da escola e o cruzamento desse estudo com as percepções dos participantes sobre o ensino-aprendizagem de inglês naquele contexto sugerem um distanciamento entre a proposta de abordagem de ensino da língua estrangeira explicitada no PPP e aquela percebida pelos participantes.

De acordo com o PPP, a concepção filosófica da escola apoia-se "numa concepção histórica cultural, buscando, através de sua práxis, interagir com os educandos para que estes se apropriem do saber acumulado historicamente e, a partir desse ponto, avançar rumo ao novo" (SANTA CATARINA, 2010, p. 3). A partir dessa concepção filosófica, podemos dizer que a escola assume o compromisso de disseminar o conhecimento historicamente produzido pelo homem por meio de uma prática reflexiva crítica (práxis). Também podemos dizer que implícita nessa concepção está a visão de aluno como agente de seu aprendizado, já que é através da práxis interativa que ele se apropria e produz conhecimentos. Dessa forma, podemos inferir que ensinar não é transmitir conhecimentos, mas criar condições para sua construção, e que o aluno não é um receptáculo no qual o conhecimento é depositado, mas um indivíduo ativo, agente do processo de aquisição e construção de conhecimentos.

Em relação ao ensino de forma geral, o PPP da escola estabelece que:

(...) O novo modelo de ensino traz consigo eixos norteadores básicos que se manifestam através da flexibilidade para atender a diversidade da sociedade e para corresponder às contínuas mudanças em situações e espaços diferentes, buscando e respeitando o encadeamento contextual, e, que, dessa forma, diversifique os caminhos e torne possível a constituição de significados, conferindo sentido à aprendizagem. $\mathrm{O}$ ensino que corresponde a essas necessidades, que educa para a autonomia e para a aprendizagem cotidiana e permanente permeia a aquisição dos saberes socialmente construídos e busca a superação do ensino tradicional. (SANTA CATARINA, 2010, p. 3).

A partir citação sobre a concepção de ensino, podemos inferir que o PPP da escola propõe o ensino voltado para atender as necessidades e mudanças sociais por meio de conteúdos que tragam significado à aprendizagem dos alunos e deem a ele autonomia necessária para continuar aprendendo ao longo da vida. Uma concepção de ensino centrada no aluno e nas demandas sociais, não no conteúdo per se.

No que tange ao currículo e à prática pedagógica de forma geral, o PPP coloca que

(...) não estarão mais centrados na transmissão dos conhecimentos, mas sim, no processo de construção e mobilização dos conhecimentos; construindo assim, uma escola onde a produção interna integra-se no desenvolvimento pessoal dos alunos e na produção social, reconhecendo-os como multiplicadores, agentes e fontes de informação. Apropriando-se do passado, a escola no presente articula o futuro. A construção e mobilização dos conhecimentos, das emoções e do fazer é a descoberta e a atualização das competências, devendo a escola admitir que também se aprenda fora dela. Cabe à escola a tarefa de integrar o conhecimento anterior ou paralelo à escolarização e as competências já desenvolvidas. A escola precisa manter viva a preocupação de preparar os alunos para uma aprendizagem duradoura; e 
para isso, é fundamental desenvolver a autonomia dos educandos, assumindo perante eles o compromisso de não apenas ensinar, mas ensinar a aprender (SANTA CATARINA, 2010, p. 4).

Com base no excerto sobre o currículo e a prática pedagógica, podemos inferir que estes são percebidos como elos de ligação para a construção e mobilização de conhecimentos, não apenas para a transmissão acrítica destes; para a educação do aluno como agente de transformação pessoal e social, não como mero repositório de conhecimentos historicamente acumulados; e para a construção da escola que ensina a aprender, não apenas a reproduzir.

No que se refere à língua estrangeira, o PPP da escola a insere na área das Linguagens, Códigos e suas Tecnologias e é orientada pelo conceito de língua como "produção humana, construída historicamente nas e pelas relações sociais (historicidade) e, como tal, é uma forma de ação sobre o outro e o mundo, marcada por um jogo de intenções e representações" (SANTA CATARINA, 2010, p. 5). Além dessa visão de língua, orientam o currículo da língua estrangeira "os conceitos de Dialogia; Polifonia; Polissemia; Interdiscursividade; Discurso; Textualidade; Texto; Coerência; Coesão" (SANTA CATARINA, 2010, p. 5). Ainda, o PPP estabelece que a condição para que o aluno se aproprie desses conceitos é o trabalho, em sala de aula, com as práticas reais de uso da língua com ênfase na produção e compreensão oral (fala-escuta), na produção e compreensão escrita (leitura-escritura) e na análise linguística (SANTA CATARINA, 2010, p. $5)$.

Em outras palavras, a língua estrangeira é concebida como discurso, uma prática social que inclui o outro, a diversidade de vozes, de significados e de gêneros textuais para representar as intenções e ideias dos atores em diferentes eventos comunicativos. Nesse sentido, o ensino-aprendizagem de língua estrangeira na sala de aula está voltado para o desenvolvimento das habilidades linguísticas e comunicativas do aluno por meio do uso da língua estrangeira em situações reais. Isso significa dizer também que a análise linguística da língua estrangeira deve partir de seu uso real em práticas discursivas, não de frases ou palavras descontextualizadas.

Embora o PPP da escola conceba a língua estrangeira/inglês como prática social e, portanto, uma ferramenta importante para o desenvolvimento pessoal e social dos alunos e oriente seu ensino por meio de práticas reais de uso da língua com ênfase na produção e compreensão oral e escrita e na análise linguística socialmente contextualizada, a própria escola não oferece condições para que tal aconteça. Algumas questões contextuais pontuais contribuem nesse sentido, como por exemplo, as políticas administrativas em relação à distribuição dos alunos nas salas de aula, à carga horária e à oferta da disciplina de língua inglesa na grade curricular, além de questões relacionadas aos professores da escola, como discutiremos a seguir.

No que tange à distribuição dos alunos nas salas de aula, o próprio PPP da escola prevê uma quantidade expressiva de alunos por turma, como observamos neste excerto: "Número de turmas e alunos no Ensino Médio em 2010: 275 alunos distribuídos em 07 turmas de primeira série; 200 alunos distribuídos em 07 turmas de segunda série; 186 alunos distribuídos em 6 turmas de terceiro ano" (SANTA CATARINA, 2010, p. 2). Em nossas visitas à escola, constatamos esses números. No primeiro semestre de 2012, havia cinco turmas de trinta e cinco estudantes em média nas salas de aula do Ensino Médio noturno, número nada favorável para o professor de inglês poder acompanhar e intermediar o processo de desenvolvimento das habilidades linguísticas e comunicativas dos alunos na língua estrangeira de forma eficaz.

Em relação à carga horária e à oferta da disciplina de língua inglesa na grade curricular, verificamos que as aulas do Ensino Médio noturno são de 39 minutos ao passo que as do diurno são de 45 minutos. Além de o tempo de aula do período noturno ser menor do que o do diurno, a disciplina de Inglês é oferecida apenas duas vezes por semana, tempo e frequência de aula que também não favorecem o ensino-aprendizagem de uma língua estrangeira que se pretende voltada para uso em eventos comunicativos. Adiciona-se a essas questões os dias de feriado, as suspensões de aula para reuniões com pais e professores, entrega de boletins, conselhos de classe, festividades, entre outros eventos marcados nos dias de aula de inglês, que diminuem ainda mais a exposição do aluno ao insumo na língua estrangeira e o tempo em que se encontra em situação de ensino-aprendizagem, dificultando a aprendizagem e reforçando percepções e crenças do senso comum, como por exemplo, a de que não se aprende inglês na escola (como mostra o estudo de Barcelos, 1999).

No que se refere aos professores da escola, há duas modalidades atualmente, os efetivos e os substitutos (ou seja, professor contratado por tempo determinado). Em relação ao professor substituto, identificamos que há uma maior quantidade desses profissionais do que de efetivos, que há uma grande rotatividade de 
professores substitutos na escola e também que seu período de contrato e tempo de permanência na escola é curto. Essa realidade, muitas vezes, não permite a esses professores o estudo do PPP da escola e muito menos sua transposição didática para a prática, já que ambas as ações demandam tempo e esforço, ou ainda a construção de laços de afeto e confiança com os alunos, impactando, de alguma forma, sua aprendizagem.

A situação dos professores de inglês da escola não é diferente. Soma-se a esse quadro, o fato de algumas vezes não haver professor substituto licenciado para assumir o ensino da língua estrangeira, e outro professor, formado em outra área de conhecimento, é convidado para preencher a ausência de um professor efetivo (como no caso de licença para tratamento de saúde), para não deixar os alunos sem aula. Uma das participantes desse estudo, a professora Mariana, é formada em Pedagogia e foi convidada a dar aulas de inglês no Ensino Médio noturno do contexto investigado, um exemplo desse tipo de prática.

Ainda, a falta da condição mínima para a seleção do professor substituto de língua estrangeira/inglês no contexto estudado, isto é, ser licenciado em sua área de atuação, situação não contemplada pela professora Mariana, reforçam a hipótese anterior e revelam um distanciamento da condição básica para o professor ensinar, ou seja, que saiba se comunicar na língua que se propõe a ensinar e que saiba principalmente ensiná-la, implícita na abordagem de ensino proposta no PPP da escola (ou será uma inconsistência entre o que está explicitado no PPP da escola e o que realmente ocorre na prática?)

As questões até aqui abordadas sugerem que, apesar de o PPP reconhecer a língua estrangeira como prática social e seu ensino como construção e mobilização de conhecimentos para atender as demandas sociais de forma significativa para os alunos, a atual política administrativa da escola tende a favorecer outras abordagens pedagógicas, como a de transmissão de conhecimento, por exemplo (FREEMAN, 2001; Freire, 2005). A quantidade expressiva de alunos por sala, a pouca oferta de aula de língua estrangeira/inglês na grade curricular e a falta de professores licenciados capacitados para ensinar o uso social da língua estrangeira (discutida mais a fundo na próxima seção) são condições tentadoras para abordagens de ensino que concebem o aluno como uma tabula rasa e um ser passivo no processo de aprender, o professor como um transmissor de conhecimento e a língua como estrutura (SILVA, 2011), indo de encontro ao explicitado no PPP da escola. Logo, em se mantendo as políticas de gerenciamento escolar atuais, inconsistências entre o ideal teórico posto no PPP da escola e o contexto escolar real tenderão a se manter, dificultando o ensinoaprendizagem da língua estrangeira no contexto investigado.

\subsection{O contexto, a língua inglesa e as práticas: relações (des)conexas}

Além das inconsistências entre o que é proposto para o ensino da língua estrangeira/inglês no PPP da escola e o contexto real, outras questões, nem sempre tão explícitas como as anteriores, impactam o ensinoaprendizagem da língua inglesa na escola. Entre essas questões, podemos citar as relações interpessoais e interdisciplinares que constituem e são constituídas nesse contexto.

Referente às relações interpessoais, a professora Maria revelou durante a entrevista com as pesquisadoras que o ambiente de trabalho e o relacionamento com os alunos é bom. Porém, ressaltou que o tempo e a frequência das aulas de inglês na grade curricular, o cansaço dos alunos do Ensino Médio do período noturno e a falta de qualificação do professor são aspectos que impactam de forma negativa o desenvolvimento de seu trabalho e refletem diretamente no processo de aprendizagem dos alunos, como mostra o excerto da conversa: "Como é ser professor de inglês nessa escola, professora Maria?" "Me identifico com a profissão, a escola e o idioma que escolhi lecionar. O problema é que tem poucas aulas de inglês, o tempo da aula é bem menor à noite e os alunos estão sempre cansados". Ao mesmo tempo, diz não se sentir preparada para desenvolver um trabalho focado no desenvolvimento da fluência dos alunos do Ensino Médio Inovador (EMI), apesar de investir nesse sentido, como mostra o excerto da conversa: "Viajo todos os anos como guia em grupos para a Disney World para aperfeiçoar minha pronúncia, mas não peguei nenhuma turma do EMI". Apesar de seu esforço pessoal no sentido de ser mais proficiente na língua que ensina, Maria não acredita que desenvolver a fluência dos alunos seja uma meta real nas turmas do Ensino Médio regular, não só pela falta de tempo, mas pelo cansaço dos alunos do Ensino Médio noturno e, principalmente, pela falta de formação continuada do professor e de conhecimento das novas tecnologias da informação e comunicação, como mostra o excerto da conversa: "Os alunos estão sempre cansados, muitos trabalham o dia todo. Eles não são fluentes depois de 7 anos estudando inglês na escola pública, porque o professor não tem cursos de educação continuada, nem de aplicação de tecnologia, que poderia ser uma ferramenta importante". 
As colocações da professora Maria em relação ao tempo e a frequência das aulas de inglês na grade curricular e a falta de qualificação do professor se alinham, em boa medida, à hipótese levantada previamente (seção 4.1) sobre o impacto da política administrativa da escola nas questões pedagógicas para o ensino de língua estrangeira no contexto estudado. Agregado a essas questões, a professora Maria também ressaltou o cansaço dos alunos do Ensino Médio do período noturno e os cursos de capacitação contínua em sua área de atuação e em Tecnologias da Informação e Comunicação (TIC) para a sala de aula, como questões que também influenciam a aprendizagem dos alunos e enfatizou que a falta destes dificulta o desenvolvimento da proficiência do aluno na língua inglesa, mesmo após sete anos de ensino obrigatório.

A professora Mariana, por sua vez, não se sente muito confortável para falar sobre o ensino de língua estrangeira/inglês, pois não é licenciada na área, como mostra o excerto da conversa: "A diretora me perguntou se eu sabia falar inglês e eu disse que havia aprendido em cursinho [curso livre de idiomas], então ela me convidou para assumir as turmas que estavam sem professor de inglês. Eu trago para eles as coisas que aprendi e um vocabulário mais voltado para o mercado de trabalho. Priorizo a tradução.” Apesar de tentar contextualizar o que ensina "vocabulário voltado para o mercado de trabalho", Mariana tem consciência de que lhe falta a formação adequada, por isso tenta manter um ambiente agradável na sala de aula, usando a "linguagem dos jovens" e tornando-se uma "companheira" para aqueles que aceitam tal posição para uma professora, como mostra o excerto da conversa: "Não sou formada em Letras-Inglês, sou formada em Pedagogia, mas tento manter um ambiente agradável na sala de aula. Uso a linguagem deles. Sou amiga deles, para aqueles que me aceitam como amiga”. Entretanto, em relação aos alunos do Ensino Médio noturno, a professora Mariana tem uma visão não muito otimista, definindo-os por sua condição socioeconômica, como mostra o excerto: "Eu posso tentar mostrar para eles [os alunos do Ensino Médio noturno] as palavras do dia-a-dia, mas o pessoal da noite é muito fraco [em conteúdo], é o pessoal que mora por aqui [perto da escola e do lixão]."

Como podemos constatar na fala das professoras participantes, as questões contextuais como a pouca oferta de aula de inglês na grade curricular, o tempo das aulas e o cansaço dos alunos do período noturno, o nível socioeconômico e as questões pessoais, como falta de formação específica e de cursos de atualização profissional, como aspectos limitantes para o desenvolvimento do trabalho do professor e da aprendizagem dos alunos.

Assim, limitadas por questões contextuais e pessoais, durante as aulas de inglês para os alunos do Ensino Médio do período noturno, as professoras participantes fazem o que consideram importante para o seu trabalho e a aprendizagem de seus alunos. Maria revisa conteúdos que, na sua perspectiva, os alunos precisam saber, como afirma o aluno André em uma de nossas conversas: "A professora Maria só dá revisão". E Mariana, por sua vez, propõe aulas com foco no desenvolvimento de vocabulário e usa algumas estratégias com fins pedagógicos para facilitar sua relação com os alunos. Uma dessas estratégias é tornar a sala de aula um ambiente agradável, usando a linguagem dos alunos, como corrobora o aluno João em uma de nossas conversas informais durante o recreio escolar: "A professora Mariana é aquela que tem Facebook! Ela é legal... fala a linguagem da gente”. A outra estratégia é atender as necessidades e interesses dos alunos, como informa o aluno Otávio: "Ela [a professora Mariana] trouxe os valores [preço] para o programa de intercâmbio... Eu quero fazer intercâmbio".

Partindo da fala de André: "A professora Maria só dá revisão” e da própria fala da professora Mariana: "priorizo a tradução" e "tento manter um ambiente agradável na sala de aula", podemos inferir que ambas as professoras participantes abordam o ensino-aprendizagem de língua estrangeira/inglês por meio da gramática e tradução. Então, diferentemente da concepção do PPP da escola, que propõe uma visão de língua como prática social, a abordagem adotada pelas professoras sugere que elas concebem a língua estrangeira como uma estrutura organizada que deve ser aprendida para, no futuro, ser usada com fins comunicativos, quem sabe!? Nesse sentido, também podemos inferir que para as professoras ensinar é transmitir conhecimentos sobre a língua (gramática, vocabulário) e aprender é receber passivamente esses conhecimentos, uma visão de aluno como receptáculo de conhecimentos, que diverge do que é proposto no PPP da escola.

Ainda, apesar de a professora Mariana ter Facebook, assim como um dos alunos entrevistados, e de trazer para a aula de inglês informações sobre programas de intercâmbio, ela não estabelece relações entre a ferramenta de comunicação social e os interesses dos alunos com a língua que ensina. A língua, vista exclusivamente como estrutura, está dissociada de seu uso, o que reforça a hipótese levantada sobre a 
concepção de língua das participantes: como estrutura a ser ensinada e, por conseguinte, de ensino como transmissão; de aprendizagem como recepção; de aluno como receptáculo (FREIRE 2005).

Em concebendo a língua como prática social, não apenas como estrutura, a professora Mariana poderia usar a ferramenta Facebook e trazer os assuntos de interesse dos alunos, como os programas de intercâmbio, para ensinar a língua estrangeira em situações comunicativas reais. No entanto, ela não consegue estabelecer a relação entre a língua estrangeira que ensina com a vida porque, como argumentam Almeida Filho (1999), Barcelos (1999), Gimenez (1999) e Woods (1996), a forma como o professor ensina está atrelada a suas concepções, conhecimentos e crenças sobre língua e ensino e aprendizagem de língua. Assim, em permanecendo as condições contextuais e pessoais no contexto investigado, as concepções, conhecimentos e crenças da escola, alunos e professores sobre ensino-aprendizagem de língua estrangeira tenderão a permanecer inalteradas e a relação entre a abordagem teórica proposta e a prática tenderá a se manter desconexa.

Ainda sobre as percepções das professoras participantes, cabe ressaltar que, em relação à capacitação do professor mencionada anteriormente, ambas apontam a formação (inicial e contínua) na área de atuação como um aspecto fundamental para que o professor possa exercer sua profissão com propriedade. Nesse sentido, em entrevista dada às pesquisadoras, a gestora escolar informou que a escola vem propiciando cursos de capacitação aos professores, apoiados ou oferecidos pelo Governo do Estado, como os voltados ao Ensino Médio Inovador ou à correção de fluxo A correção e fluxo é uma medida política e estratégica utilizada para adequar a série à idade dos alunos no ensino fundamental. O objetivo da correção é acabar com a distorção idade-série, considerada um dos maiores problemas enfrentados na educação pública brasileira. Um dos principais elementos aplicados no processo de correção de fluxo é a aceleração de aprendizagem, uma estratégia pedagógica de solução emergencial e intensiva para os alunos defasados (MENEZES; SANTOS, 2002).

No entanto, esse tipo de capacitação imposta à escola por instâncias governamentais superiores, às vezes preparadas por especialistas distantes dela, sugere que a escola ainda se mantém presa a um modelo de gestão gerencialista que, muitas vezes, dificulta a autonomia dos professores, no sentido de poderem escolher cursos específicos para sua área de atuação, além de não propor alternativas para práticas de ensino tradicionais (CAMPOS; SCHEIBE, 2007, apud CERNY, 2011), como a de gramática e tradução identificada para o ensino-aprendizagem de língua estrangeira/inglês no contex to estudado.

Não estamos aqui sugerindo que cursos de capacitação geral apoiados pelo governo, como os citados anteriormente, não são importantes para a formação do professor. Muito pelo contrário, eles podem contribuir para ampliar a visão do professor sobre questões político-pedagógicas mais amplas e que impactam o ensino-aprendizagem no contexto escolar e na sociedade. Entretanto esses cursos não dispensam os de formação específica na área de conhecimento do professor, uma conquista política ainda a ser feita.

Também observamos esforços da escola para integrar-se à comunidade na qual está inserida por meio de projetos de caráter inclusivo. Dentre os projetos, podemos citar o Nosso Lixo de Cada Dia, um projeto de reciclagem de lixo desenvolvido em um lixão próximo à escola, realizado com alunos e comunidade, que visa não somente à conscientização ambiental, mas principalmente à capacitação das famílias cuja subsistência depende desse trabalho, segundo a gestora da escola em entrevista dada às pesquisadoras. Além do projeto Nosso Lixo de Cada Dia, a escola oferece aulas complementares no contra turno, no sentido de melhorar os índices de desempenho dos alunos da escola e evitar a evasão escolar. A escola oferece aulas de reforço em português e matemática para os alunos do Ensino Médio regular, do período diurno, como informou a gestora escolar em entrevista às pesquisadoras.

Porém, nessas e em outras iniciativas, a disciplina de língua inglesa, devido às contingências atuais, também está distanciada. As demais disciplinas da grade curricular, no entanto, integram aos seus objetivos de ensino específicos, objetivos educacionais mais amplos, que visam a melhorar a condição de vida da comunidade e a formação de cidadãos.

Explicar o distanciamento da disciplina de língua inglesa nos projetos de caráter inclusivo da escola não é uma tarefa simples, pois demanda um entendimento de relações nem sempre perceptíveis para observadores externos ao contexto, como é o nosso caso, e um tempo de vivência na escola muito maior do que aquele demandado no primeiro módulo da disciplina de Estágio Supervisionado (20h de estudo e observação do 
contexto escolar). Porém, tentaremos levantar hipóteses com base no conceito de língua estrangeira no processo de ensinar e aprender a língua estrangeira na escola, na percepção de Almeida Filho (2007).

Para o autor, a língua estrangeira é um conceito complexo sobre o qual o professor precisa refletir no exercício de sua profissão, já que impacta a forma como ele aborda o ensino e como o aluno aprende. Na concepção do autor,

[...] a língua estrangeira pode significar a língua dos outros ou de outros, ou língua dos antepassados, de estranhos, de bárbaros, de dominadores, ou língua exótica. A compreensão do termo se aperfeiçoa se o tomarmos como língua que só no princípio é de fato estrangeira, mas que se desestrangeiriza ao longo do tempo de que se dispõe para aprendê-la (ALMEIDA FILHO, 2007, p. 12-13) [Itálico no original].

Como sugere o conceito de língua estrangeira de Almeida Filho, no início da aprendizagem, a língua estrangeira pode significar a língua dos outros, de estranhos, mas quando aprendida, a língua se desestrangeiriza e passa a constituir o indivíduo, servindo como mais uma ferramenta de ação no mundo. Para as professoras participantes do estudo, no entanto, o conceito ainda parece estar em sua fase inicial, a língua estrangeira é a língua dos outros. Assim, ao ensinarem essa língua sentem-se estranhas a ela, já que não se apropriaram dela, e ensinam sobre ela em vez de seu uso em eventos comunicativos.

Ainda, por não terem desestrangeirizado o conceito de língua estrangeira, fazer a relação entre a língua que ensinam e a sua função social num contexto alheio a ela pode não ter sentido algum para as professoras participantes da pesquisa. Dessa forma, a disciplina de inglês e suas professoras não se engajam nos projetos socioeducativos da escola, como fazem os professores das outras disciplinas da grade curricular. Logo, a abordagem de ensino das professoras de inglês, ou seja, sua concepção de língua e ensino-aprendizagem de língua (ALMEIDA FILHO, 1999), também está impregnada da visão de língua como a língua dos outros.

A percepção de língua estrangeira como a língua dos outros e, portanto, sem função social no contexto onde é ensinada, também pode explicar o distanciamento entre a proposta para o ensino da língua estrangeira/inglês no PPP da escola e a abordagem de ensino das professoras participantes. Como mencionado anteriormente, a professora Maria dá aulas de revisão com foco nas formas da língua dissociada de seu uso, e a professora Mariana, por sua vez, propõe aulas com foco no desenvolvimento de vocabulário/tradução para seus alunos. Ambas as professoras têm uma abordagem de ensino de língua de uma perspectiva estruturalista. Já o PPP da escola propõe uma visão de língua voltada para comunicação, o que implica uma abordagem de ensino de uma perspectiva comunicativa. Assim, em se mantendo o conceito de língua estrangeira como a língua dos outros, as relações de distanciamento entre o ideal e o real identificadas nesse estudo tenderão a se manter.

Além do distanciamento entre a proposta de ensino de língua estrangeira no PPP e a percepção dos participantes sobre ele e o distanciamento (ou do encolhimento?) da disciplina de inglês das propostas socioeducativas da escola, os alunos do Ensino Médio noturno do contexto investigado têm características particulares. Como colocado anteriormente, esse contexto é constituído por alunos com idade entre 16 e 20 anos com histórias escolares diversas. Uns com idade adequada ao nível de escolaridade, outros, nem tanto. Uns são apenas estudantes, outros estudam e trabalham. Uns iniciam e terminam o Ensino Médio regular, outros migram para o Ensino Supletivo no terceiro bimestre escolar. Uns migram para o Ensino Supletivo ao saberem que não vão recuperar as notas baixas e passar de ano, outros migram por se sentirem desconfortáveis entre colegas mais jovens e ainda outros migram pelo cansaço físico depois de um dia inteiro de trabalho.

Independentemente do motivo, os alunos do Ensino Médio noturno que migram para outras modalidades de ensino, apesar de satisfazerem uma necessidade pessoal, sofrem certo grau de descontinuidade em seu processo de aprendizagem e rompem laços afetivos estabelecidos com professores e colegas. Em um estudo sobre jovens e adultos como sujeitos de conhecimento e aprendizagem, Oliveira (1999) alerta que alunos adultos têm vergonha de frequentar a escola, especialmente quando inseridos em turmas com idade adequada para sua escolarização, sentem-se humilhados e tornam-se inseguros quanto a sua própria capacidade para aprender. Nesse sentido, o rompimento de laços afetivos, no caso do aluno adulto que migra do Ensino Médio para o Supletivo, tende a acentuar e/ou manter as características psicológicas negativas que ele traz consigo para o contexto escolar, elevando seu filtro afetivo e dificultando ainda mais sua aprendizagem, como sugere a Hipótese do Filtro Afetivo de Krashen (2002). 
Dos alunos que permanecem no Ensino Médio, alguns não se engajam com afinco em seu processo de aprendizagem, contentam-se com o mínimo para passar de ano, como evidencia uma das conversas informais entre os alunos e as pesquisadoras durante a pausa para o recreio escolar: "Você aprende inglês na escola, Ana?" "Daquele jeito, né?" "E você, André?" "Não gosto da aula, não gosto de inglês. A professora Maria só dá revisão." "E você, Paulo?" "Eu estudo para passar de ano". "E você, Renata? "Às vezes as aulas são boas, mas a gente não aprende nada de verdade, não sabe falar nada na língua". Outros alunos se afeiçoam ao professor por estarem juntos há muito tempo, como sugere a fala de Eduarda: "Gosto muito da professora Maria, ela é minha professora desde a sexta série”. Outros entretanto se afeiçoam ao professor por sua maneira de ser no mundo, como mostra a fala de João: "A professora Mariana é aquela que tem Facebook. Ela é legal... fala a linguagem da gente" e de Carla: "Eu escuto música em inglês e tenho Facebook. Ela está no meu Face também." Mas a maioria dos alunos considera ter um bom relacionamento com as professoras de inglês da escola.

Como mostram as falas dos alunos, Ana considera que não aprende como deveria, André não gosta da aula e da disciplina, relacionando esse fato à abordagem de ensino da professora, Paulo limita-se a estudar para passar de ano, pois garante o mínimo para dar prosseguimento à sua formação básica, e Renata argumenta que não aprende de verdade porque não sabe falar na língua estrangeira. Já o tempo fez Eduarda gostar da professora Maria e João e Carla têm certo grau de afinidade com a professora Mariana por terem Facebook, por falarem a mesma linguagem e por gostarem de ouvir música em inglês, no entanto, não canalizam esses laços para a aprendizagem. Tanto as posturas de desafeto do primeiro grupo de alunos quanto as de afeto do segundo não favorecem o processo de aprendizagem. Os primeiros não percebem que não valorizar o que é ensinado não contribui para desenvolver e/ou mudar sua condição cognitiva e socioafetiva; pelo contrário, esta tenderá a se manter ou tardará a se transformar. Os segundos, pelo fato de não canalizarem a afinidade/afetividade com a professora para seu aprendizado, também não contribui para mudar a situação de aprendizagem ou potencializar outras conquistas.

Ao questionarmos as professoras participantes sobre suas abordagens de ensino e estratégias para manter o aluno atento na aula e motivá-los a aprender, Maria afirmou: "Eu me comunico mais em português do que em inglês com os alunos para que eles compreendam o que eu falo e não percam a atenção na aula". Já Mariana disse: "Eu priorizo a tradução e tento manter um ambiente agradável na sala de aula, usando a linguagem deles. Outro dia um aluno me pediu informação sobre programa de intercâmbio e eu trouxe para ele".

Como podemos perceber, as professoras procuram usar abordagens e estratégias de ensino, visando a gerar maior interesse nos alunos para aprender. Enquanto a professora Maria comunica-se com os alunos mais em português do que em inglês para mantê-los atentos e motivados, a professora Mariana procura priorizar a tradução, manter um ambiente agradável na sala e atender as inquietações dos alunos, trazendo informações sobre viagens de intercâmbio, por exemplo. No entanto, as estratégias usadas pela professora Maria não são percebidas por seus alunos como favoráveis à aprendizagem. No caso da professora Mariana, os alunos dão pistas que poderiam ser usadas para abordar o ensino da língua de forma diferente da tradução, como por exemplo, os temas postados nas redes sociais ou gêneros textuais como músicas e panfletos de propaganda de programas de intercâmbio, mas ela não as percebe como tal. Logo, em se mantendo as abordagens e estratégias de ensino, as percepções de professores e alunos sobre ensinoaprendizagem de língua estrangeira tenderão a se manter (des)conexas.

\section{UMA ABORDAGEM HOLÍSTICA PARA O ESTÁGIO SUPERVISIONADO: RESULTADOS E CONSIDERAÇÕES FINAIS}

Como mencionado anteriormente, este estudo buscou uma compreensão do contexto da escola campo de estágio por meio da percepção dos atores desse contexto, as professoras de inglês, Maria e Mariana, e os alunos do Ensino Médio noturno sobre suas experiências de ensino-aprendizagem, visando a um estágio de docência socialmente situado no contexto investigado.

De forma geral, a análise dos dados revelou que há um distanciamento conceitual entre o que é proposto no PPP da escola em relação ao ensino da língua inglesa e a percepção dos participantes sobre o que acontece na escola. No PPP, a língua estrangeira é concebida como discurso, uma ferramenta para comunicação e seu ensino orientado para o desenvolvimento das habilidades linguísticas e comunicativas dos alunos nessa 
língua. Na prática, a língua estrangeira é percebida como estrutura, orientando práticas pedagógicas com foco nas formas da língua.

A análise dos dados também revelou que algumas políticas administrativas do contexto estudado não privilegiam uma forma de abordagem de ensino diferente da transmissão de conhecimento (FREEMAN, 2001; FREIRE, 2005), pelo menos no que concerne à língua estrangeira. Assim, em se mantendo políticas que propiciem terrenos férteis para concepções de ensino como transmissão de conhecimento, de professor como transmissor e de aluno como receptor passivo de conhecimento (SILVA, 2009; 2011), inconsistências, distanciamentos e contradições entre o que está posto no PPP para o ensino de língua estrangeira e a sua prática tenderá a se manter.

A análise dos dados ainda sugeriu que a percepção que as professoras participantes têm do conceito de língua estrangeira influencia a relação que elas têm com sua própria disciplina, a relação da sua disciplina com outras disciplinas da grade curricular, a sua relação com os alunos, afetando, por conseguinte, sua abordagem de ensino e sua postura política no contexto onde trabalham e possivelmente vivem. Em conceituando a língua estrangeira como a língua do outro (ALMEIDA FILHO, 2007), as relações interpessoais e interdisciplinares que o professor estabelece em seu contexto de trabalho tenderão a ser desconexas e/ou de encolhimento, provocando posturas político-sociais e pedagógicas da mesma ordem, que explicaria a abordagem de língua das participantes apenas como estrutura e o distanciamento da disciplina de inglês dos projetos educacionais propostos pela escola.

No entanto, em “desestrangeirizando" o conceito, a língua passa a ser percebida como a língua que também constrói o outro e é construída por ele. Logo, as relações interpessoais e interdisciplinares que o professor estabelece em seu contexto de trabalho tenderão a ser mais próximas (afetuosas, quem sabe!) e provocar posturas político-sociais mais engajadas e mais responsáveis no contexto onde vive e trabalha, situações contextuais essas que poderiam, por extensão, provocar uma visão de língua diferente da identificada, motivar a participação da disciplina e dos professores de inglês em desafios educacionais mais amplos do que a própria disciplina, ampliando a rede de relações desta e de seus agentes e se alinhando às concepções teóricas do PPP da escola para a língua estrangeira.

Com base nos resultados, este estudo sugere, portanto, um estágio de docência voltado para uma abordagem holística de ensino-aprendizagem de língua estrangeira em contraponto a uma abordagem por partes desconexas. Segundo Brown (2001, p. 49), a abordagem holística de língua "é um modo de vida educacional. [Essa abordagem ajuda] as pessoas a construírem conexões significativas entre o aprendizado do dia-a-dia e o aprendizado escolar”. Essa abordagem poderia, por exemplo, partir do ensino de língua estrangeira por meio de temas socialmente relevantes para a comunidade escolar, como os propostos pela própria escola, por exemplo, dando sentido a uma concepção de língua como prática social, de aluno como agente de seu próprio aprendizado e de professor como mentor intelectual do processo, seguindo ao mesmo tempo as orientações teóricas do PPP da escola (e da disciplina de Estágio Supervisionado também) e provocando outras posturas em relação ao ensino-aprendizagem da língua estrangeira/inglês no contexto estudado.

Sabemos que as percepções aqui discutidas são constituídas e constituem uma rede sociohistórica e cultural muito mais ampla e que não são fáceis de desenredar, explicar e muito menos de desconstruir para construir outras redes de percepções. Mas o fato de a investigação sobre a percepção do processo de ensinoaprendizagem de língua estrangeira/inglês nos revelar a complexidade da rede nele envolvido, aumenta o potencial de possibilidades para o nosso estágio de docência no contexto investigado, além das iluminações que nos proporciona ao pensarmos as próximas experiências pedagógicas que teremos em nosso processo de aprender a ensinar.

Por fim, mas não menos importante, o exercício de investigação para compreender o contexto de docência, visando à implementação de aulas socialmente situadas, demandado pela disciplina de Estágio Supervisionado, proporcionou uma reflexão profunda sobre o contexto estudado e apontou caminhos para uma docência significativa naquele e para aquele contexto, validando, em boa medida, o modelo de formação profissional proposto para a modalidade a distância. 


\section{REFERÊNCIAS}

ABRAHÃO, M. H. V. Teoria e prática na formação pré-serviço do professor de língua estrangeira. In: GIMENEZ, T. (Org.). Trajetórias na formação de professores de línguas. Londrina: Universidade Estadual de Londrina Editora, 2002. p. 59-76.

ALMEIDA FILHO, J. C. P. de. Análise de abordagem como procedimento fundador de autoconhecimento e mudança para o professor de língua estrangeira. In: ALMEIDA FILHO, J.C.P. de (Org.). O professor de língua estrangeira em formação. Campinas, SP: Pontes, 1999.

ALMEIDA FILHO, J.C.P. Dimensões comunicativas no ensino de linguas. 4. ed. Campinas: Pontes, 2007.

BARCELOS, A. M. A cultura de aprender línguas (inglês) de alunos no curso de Letras. In: ALMEIDA FILHO, J.C.P. de (Org.). O professor de língua estrangeira em formação. Campinas, SP: Pontes, 1999. p. 157177.

BARTLETT, L. Teacher development through reflective teaching. In: RICHARDS J.C.; NUNAN, D. (Eds.). Second language teacher education. New York: Cambridge University Press, 1990. p. 202-214.

BROWN, H. D. Teaching by Principles: an interactive approach to language pedagogy. 2. ed. New York: Longman, 2001.

CERNY, R. Z. Organização escolar. Florianópolis: LLE/CCE/UFSC, 2011.

CRUZ, A.; REIS, S. O diário como instrumento de apoio na socialização de uma professora de inglês. In: GIMENEZ, T. (Org.). Trajetórias na formação de professores de línguas. Londrina: Universidade Estadual de Londrina Editora, 2002. p. 95-107.

DENZIN, N.K; LINCOLN, Y. (Eds.). Collecting and interpreting qualitative materials. Thousand Oaks: Sage Publications, 1998.

ELBAZ, F. The teacher's "practical knowledge": report of a case study. Curriculum Inquiry, v. 11, n. 1, p. 43$71,1981$.

FREEMAN, D. Second language teacher education. In: R. Carter \& D. Nunan. The Cambridge Guide to Teaching English to Speakers of Other Languages. Cambridge: Cambridge University Press, 2001.

FREIRE, P. A Pedagogia do Oprimido. 42 ed. Fontes, 2005.

GIMENEZ, T. (Org.). Trajetórias na formação de professores de línguas. Londrina: Ed. UEL, 2002.

. Reflective teaching and teacher education contributions from teacher training. Linguagem \& ensino, v. 2, n.2, p. 129-143, 1999.

GIROUX, H. A. Os professores como intelectuais: rumo a uma pedagogia crítica da aprendizagem. Porto Alegre: Artes Médicas, 1997.

JOHNSON, K.; FREEMAN, D. Teacher learning in second language teacher education: a socially-situated perspective. Revista Brasileira de Linguística Aplicada, v.1, n.1, p. 53-69, 2001.

KRASHEN, S. D. Second language acquisition and second language learning. Oxford: Pergamon Press Inc., 1981; Internet Edition, December 2002. Disponível em: <

http://www.sdkrashen.com/SL_Acquisition_and_Learning/index.html> Acesso em Julho 2012.

LIBERALI, F.C. Agente e pesquisador aprendendo na ação colaborativa. In: GIMENEZ, T. (Org.).

Trajetórias na formação de professores de línguas. Londrina: UEL, 2002. p. 109-127.

LIBERALI, F. C. Formação crítica de educadores: questões fundamentais. Taubaté, SP: Cabral Editora e Livraria Universitária, 2008.

MAGALHÃES, M. C. C. O professor de línguas como pesquisador de sua ação: a pesquisa colaborativa. In: GIMENEZ T. (Org.). Trajetórias na formação de professores. Londrina: ED. Universidade Estadual de Londrina, 2002. p. 39-58. 
MENEZES, E.T.; SANTOS, T.H. Correção de fluxo escolar. In: DICIONÁRIO Interativo da Educação Brasileira - EducaBrasil. São Paulo: Midiamix Editora, 2002. Disponível em:

$<$ http://www.educabrasil.com.br/eb/dic/dicionario.asp?id=170> Acesso em 07/01/2013.

MEURER, J. L. Uma dimensão crítica do estudo de gêneros textuais. In: MEURER, J. L.; MOTTAROTH, D. (Orgs.). Gêneros textuais e práticas discursivas: subsídios para o ensino da linguagem. Bauru, SP: EDUSC, 2002. p. 17-29.

MOITA LOPES, L. P. Oficina de linguística aplicada. 5 ed. Campinas: Mercado de Letras, 1996.

MOTA, M. B. Linguística aplicada I. Florianópolis: LLE/CCE/UFSC, 2010.

NÓVOA, A. Professores: imagens do futuro presente. Portugal: Instituto de Educação Universidade de Lisboa; Realgráfica artes gráficas Lda., 2009.

OLIVEIRA, M. K. Jovens e adultos como sujeitos de conhecimento e aprendizagem. REUNIÃO ANUAL DA ANPEd, 22., Caxambu, setembro de 1999. Anais... Disponível em:

http://educa.fcc.org.br/pdf/rbedu/n12/n12a05.pdf Acesso em 21/01/2013.

ORTENZI, D.I.B.G.; MATEUS, E.F.; REIS, S.; GIMENEZ, T. Concepções de pesquisa de futuros professores de inglês. In: GIMENEZ, T. (Org.). Trajetórias na formação de professores de línguas. Londrina: UEL, 2002. p. 157-181.

RICHARDS, J.C. The language teaching matrix. Cambridge: Cambridge University Press, 1990.

RICHARDS, J. C. Beyond training. Cambridge: Cambridge University Press, 1998.

SANTA CATARINA. Secretaria do Desenvolvimento Regional. Gerência Regional da Educação. Escola de Educação Básica Cecília Rosa Lopes. Projeto Político Pedagógico. São José, SC, 2010.

SCHÖN, D. The reflective practitioner. London: Temple Smith, 1983.

SILVA, M. da. Constructing the teacher process from the inside out: how pre-service teachers make sense of their perceptions of the teaching of the four skills. Dissertação (Mestrado em Letras/Inglês) - Programa de PósGraduação em Letras/Inglês e Literatura Correspondente, Universidade Federal de Santa Catarina, Florianópolis, 2003.

SILVA, M. Constructing the teaching process from inside out: how pre-service teachers make sense of their perceptions of the teaching of the four skills. TESL-EJ: teaching English as a second or foreign language, v. 9. n. 2, p. 1-19, 2005.

SILVA, M. Teacher knowledge in English language teacher education: weaving its meaning in the writings of three Brazilian applied linguists. Tese (Doutorado em Letras/Inglês) - Programa de Pós-Graduação em Letras/Inglês e Literatura Correspondente, Universidade Federal de Santa Catarina, Florianópolis, 2009.

SILVA, M. $6^{o}$ Período: Estágio Supervisionado I. Florianópolis: LLE/CCE/UFSC, 2011.

SMYTH, J. Teachers' work and the politics of reflection. American Educational Research Journal, v. 29, n.2, p. 267-300, 1992.

TELLES, J. A. A trajetória narrativa: histórias sobre a prática pedagógica e a formação do professor de línguas. In: GIMENEZ, T. (Org.). Trajetórias na formação de professores de línguas. Londrina: Universidade Estadual de Londrina, 2002. p. 15-38.

TELLES, J.A. Modos de representação: o espetáculo teatral como dispositivo de reflexão e representação do desenvolvimento do professor. In: ABRAHÃO, M.H.V. (Org.). Prática de ensino de língua estrangeira: experiências e reflexões. Campinas, SP: Pontes Editores, 2004. p. 61-105.

WALLACE, M. J. Training foreign language teachers: a reflective approach. Cambridge: Cambridge, 1991. p. 186.

WOODS, D. Teacher cognition in language teaching: beliefs, decision-making, and classroom practice.

Cambridge: Cambridge University Press, 1996. 
ZEICHNER, K. M.; LISTON D.P. Teaching Student Teachers to Reflect. Harvard educational revierw, v. 57, n.1, p. 23-48, 1987.

Recebido em 11/11/13. Aprovado em 19/12/13. 